\title{
The Impact of Social Support on Students' Behavior in the Context of Iraqi Medical Education
}

\author{
I. D. Al-Hasani ${ }^{1}$, H. S. Salih ${ }^{1}$, A. T. Abdul Wahid ${ }^{2}$, Mohammed Jabarah ${ }^{3 *}$ (D) \\ ${ }^{1}$ Medical Student, College of Medicine, University of Baghdad, Baghdad, Iraq; ${ }^{2}$ Department of Surgery, College of Medicine, \\ University of Baghdad, Baghdad, Iraq; ${ }^{3}$ Department of Pharmacology, College of Medicine, University of Baghdad, \\ Baghdad, Iraq
}

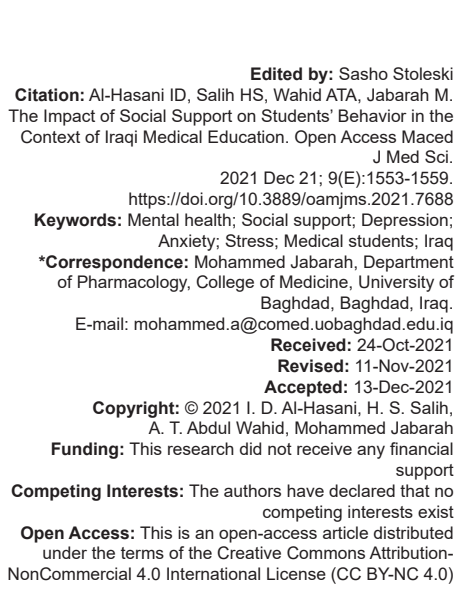

\section{Abstract}

BACKGROUND: Mental health problems are reflected and linked to human behavior in many aspects. Medical students are susceptible to a wide variety of events that compromise their mental well-being, social life as well as their academic achievements.

AIM: This study aimed to find the impact of social support on medical students' behavior in Iraq via assessing their depression, anxiety, and stress status.

METHODS: A cross-sectional online survey-based study targeted all medical students in Iraq. The employed questionnaires covered mental health status of participants by evaluating their perceptions of depression, anxiety, and stress using. Data were analyzed using the Statistical Analysis System.

RESULTS: The study revealed a significant influence of social support on students' perceptions of depression and anxiety, but not of their perception of stress.

CONCLUSION: Lending social support to medical student is crucial to improve their depression and anxiety with al the positive results that the support brings to their behavior and social life. However, they need more than the socia support to keep them safe from academic and daily life stressors.

\section{Introduction}

The term "social support" frequently appears in discussions of relationships. It means having friends and other people, including family, to turn to them in times of need or crisis to provide you a broader focus and positive self-image [1], [2]. In addition, social support enhances the quality of life and gives a buffer against unfavorable life events. Furthermore, social support can be emotional (sometimes called non-tangible) support which refers to the actions human beings take to make anybody else feel cared for [1], [2].

During the past three decades, researchers have shown remarkable interest in the phenomena of social support, especially in the context of health. Prior work had observed that those with high quality or quantity of social networks have a diminished threat of mortality in contrast to those have low quantity or quality of social relationships, even after statistically controlling for baseline health status [3].

In fact, social isolation itself was once recognized as an independent essential risk element for all-cause mortality. Moreover, people thought to be confronted with increased loss in the context of fewer social resources and a lower adequacy of social support as they are growing older, both in subjectively perceived guide and frequency of contacts due to expanded responsibilities and overall lifestyle stresses, particularly among medical students [4], [5]. Furthermore, it is commonly agreed that social support performs an advisable position, in the preservation of mental health and psychological well-being, and reduces the hazard of depression.

There are two models which are common in explaining how social support influences psychological distress, the direct effect model and the indirect (buffer) effect model [6]. The direct effect implies that social relationships have a really useful effect on health, regardless of existence situation; whereas the stress-buffering effect implies that social relationships only have a recommended effect for humans exposed to stressors, such as poor lifestyle activities and hardships over time. In this instance, social support acts to buffer the effects of stress by means of improving personal coping skills such as self-esteem and self-efficacy. Through strengthening of the coping mechanisms, the negative emotional reaction to a disturbing event will be reduced or the 
negative physiological responses on health, through the immune system, will be dampened [7], [8], [9], [10].

On the other hand, psychological resilience is an important section of positive psychology. It is a systematic and dynamic adaptive process, which can promote people to actively deal with adversity or stress and attain proper adaptation and improvement [11]. In addition, relevant literature showed that the individual's psychological resilience was highly associated with mental health status, and humans with higher psychological resilience level had higher mental health level, while individuals with decreased psychological resilience stage easily suffer from negative feelings such as anxiety and depression [12].

Mental health problems can significantly increase global medical burden, as a previous study estimated that mental health problems accounted for $12 \%$ of the global economic burden in 2000 and could reach $15 \%$ by 2020 [13].

Among risk and protective factors associated with psychological well-being among medical students, self-esteem and relationship with parents play a relevant role [14]. In addition, self-esteem is based on the conception of one's own worthiness, which is decided not only by self-perceptions but also by means of interpretations of feedback from significant others like close friends and family contributors. Moreover, a high level of self-esteem is usually related with good psychological well-being and happiness [15], [16].

It was assumed that between psychological distress and social support a direct association (Figure 1) [17] that goes each ways. Furthermore, it is expected that such associations will also be determined in this research as it constitutes the fundamental aim of the study.

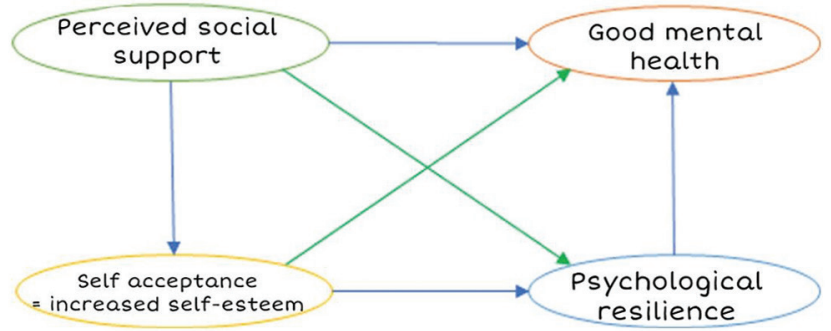

Figure 1: The theoretical model of perceived social support, selfacceptance, psychological resilience, and mental health based on the following three theoretical hypotheses: (1) Self-acceptance has a mediating effect between perceived social support and mental health; (2) Psychological resilience has a mediating effect between perceived social support and mental health; (3) Self- acceptance and psychological resilience have multiple mediating effects between perceived social support and mental health [17]

Problems affecting mental health are recognized problems among all populations and there is an increased research interest and focus on this point worldwide. On the other hand, there are few studies done in the Middle East, none of them are among Iraqi medical students who are exposed to a wide variety of stressors and possible risk factors for depression; for example, sedentary lifestyle, extreme stress during examination periods, lack of enough free time and recently the general stress of the pandemic of COVID-19, in addition to other possible mental disorders such as stress and anxiety. Therefore, the present study was aimed to reveal the impact of socioemotional support and mental health of Iraqi medical students on their behaviors.

\section{Methods}

A web-based descriptive cross-sectional questionnaire-based study involved almost all medical students in Iraq except those who did not give consent to use their information. The study conducted between November 22, 2020 and February 1, 2021. Convenient sampling was performed and the questionnaire filled by 870 medical students from different medical schools in Iraq. Ethical approval was obtained from the Research Ethics Committee at the College of Medicine/University of Baghdad.

The survey was conducted as a Google forum on the internet due to the lockdown and COVID-19 situation in Iraq. The survey was sent to representatives from medical schools who publish it on the media of their relevant universities. In addition, participants were asked to give their consent regarding the information that the study aimed to fulfill through the questionnaires. The information was collected in an anonymous way in which participants were not obligated to provide their names, emails, or their contact details.

The survey was divided into two sections. The first section included the independent variables, which was the social support questionnaire that was taken from a previous study in this regard [18]. Nine questions of the social support were designed to be answered by one out of four choices: definitely false, probably false, probably true, definitely true. A score from 0 to 3 was given to the answers, respectively. The summation of the score leads to categorize the social support into three categories: (0-9) low social support, (10-19) borderline social support, (20-27) high social support. On the other hand, the second section which included the dependent variables, was the depression, anxiety, and stress scale (DASS-21). It consists of three subscales concerning depression, anxiety, and stress. Those within the subscale of depression are questions $3,5,10,13,16,17$, and 21 . The total depression subscale score was divided into normal (0-9), mild depression (10-12), moderate depression (13-20), severe depression (21-27), and extremely severe depression (28-42). Moreover, questions 2, 4, 7, 9, 15,19 , and 20 formed the anxiety subscale. The total anxiety subscale score was divided into normal (0-6), 
mild anxiety (7-9), moderate anxiety (10-14), severe anxiety (15-19), and extremely severe anxiety (20-42). Finally, questions $1,6,8,11,12,14$, and 18 formed the stress subscale. The total stress subscale score was divided into normal (0-10), mild stress (11-18), moderate stress (19-26), severe stress (27-34), and extremely severe stress (35-42).

\section{Statistical analysis}

The Statistical Analysis System (2012) [19] program was used to detect the effects of different factors on study parameters. The least significant difference -LSD test (Analysis of Variance-ANOVA) was used to significantly compare between means. However, Chi-squared test was used to significantly compare between percentages 0.05 and 0.01 probabilities.

\section{Results}

A total number of 870 medical students who study in Iraq were included in the study; 604 (69.43\%) of the respondents were females and 266 (30.57\%) were males (Table 1).

Table 1: Distribution of respondents according to their gender and year of study

\begin{tabular}{llll}
\hline Variable & No. (Total = 870) & $\%$ & p-value \\
\hline Gender & & & \\
$\quad$ Male & 266 & 30.57 & $*$ \\
$\quad$ Female & 604 & 69.43 & \\
Year of study & & & \\
1 & 123 & 14.14 & \\
2 & 196 & 21.53 & \\
3 & 198 & 22.76 & \\
4 & 126 & 14.48 & \\
5 & 123 & 14.14 & \\
6 & 104 & 11.95 & \\
${ }^{*} \mathrm{p} \leq 0.05,{ }^{* *} \mathrm{p} \leq 0.01$. & &
\end{tabular}

In addition, distribution of participants according to social support groups was presented in (Table 2 and Figure 1).

Table 2: Distribution of participants according to social support groups

\begin{tabular}{lll}
\hline Social support group (Score) & No. (mean) & $\%$ \\
\hline Low support (0-9) & $122(5.88)$ & 14.02 \\
Borderline support (10-19) & $515(14.71)$ & 59.20 \\
High support (20-27) & $233(23.68)$ & 26.78 \\
Total & 870 & 100 \\
Chi-squared & & $286.041^{\star *}$ \\
\hline${ }^{* *} \leq 0.01$. & &
\end{tabular}

\section{Discussion}

The present study aimed to determine the association between social support and behaviors and mental conditions (depression, anxiety, and stress) by using data from a convenient sample of 870 medical students from different stages in different universities in Iraq in 2020-2021. The study was based on a detailed survey that examined the amount and quality of socioemotional support among those medical students and how it is reflected on their different everyday behaviors in addition to their mental health quality.

The study found that $(12.41 \%)$ students were mildly depressed, (27.70\%) were moderately depressed, (14.14\%) were severely depressed, and $(20.11 \%)$ were extremely depressed (Table 3$)$. These rates were relatively high in comparison with another study conducted in Kurdistan that revealed that only $(52.1 \%)$ of students have depression [20].

Depression reflects on quite many aspects of the behavior. Students with depression have no longer interest in their daily activities in a manner that makes them lose the joy and pleasure [21]. In addition, anger, irritability, and concentration problems are all symptoms that are provoked by depression and contribute to devastating behavioral consequences.

It is known that depression causes lack of sleep or causes over sleeping that compromises students' grades, cognitive state, and their academic achievement [22]. Moreover, persistent feelings of sadness jeopardize students' social life by reducing their interpersonal skills and making them repulsive and unaccepted by their peers. On the other hand, the study revealed that $7.59 \%, 24.02 \%, 15.63 \%$, and $34.02 \%$ were mildly, moderately, severely, and extremely anxious. These data were relatively high in comparison with those from a study conducted in Kurdistan that revealed that $61.5 \%$ of students have anxiety [20].

Anxiety could induce symptoms that are clearly observed in the students' behavior. Students with anxiety tend to avoid the social interaction and the involvement with the other students. Furthermore, the over thinking that is triggered by anxiety can cause lack of concentration, problems with sleep, and feelings of dissociation [21], [22], [23]. In addition, students with anxiety tend to avoid the places or the situation that cause an embracement or make them feel trapped.

The other important finding of the current study was that there was a high prevalence of stress among medical students in Iraq as $17.24 \%, 19.54 \%, 21.61 \%$, and 9.89 of participants had mild, moderate, severe, and highly severe stress, respectively. These data were higher than those reported by a study in Saudi Arabia [24], Republic of Iran [25], and the United Kingdom [26] which revealed that $57 \%, 61.3 \%$, and $31.2 \%$ of participants were under stress, respectively.

Stressors have a big effect on mood, sense of well-being, behavior, and health [27]. In addition, acute responses to stress in young, healthy individuals may be adaptive and typically do not impose a health burden. However, if the threat is unremitting, particularly in older or unhealthy individuals, the long-term impacts of stressors can have a bad effect on health like 
Table 3: Classification of participants according to depression, anxiety, and stress groups

\begin{tabular}{|c|c|c|c|c|c|c|}
\hline \multirow[t]{2}{*}{ Group measurement } & \multicolumn{2}{|c|}{ Depression group } & \multicolumn{2}{|c|}{ Anxiety group } & \multicolumn{2}{|l|}{ Stress group } \\
\hline & No. (\%) & Mean score (Range) & No. (\%) & Mean score (Range) & No. $(\%)$ & Mean score (Range) \\
\hline Normal & $223(25.63)$ & $6.07(0-9)$ & $163(18.74)$ & $4.51(0-7)$ & $276(31.72)$ & $6.93(0-14)$ \\
\hline Mild & $108(12.41)$ & $12.55(10-13)$ & $66(7.59)$ & $8.61(8-9)$ & $150(17.24)$ & $16.44(15-18)$ \\
\hline Moderate & $241(27.70)$ & $17.85(14-20)$ & $209(24.02)$ & $12.92(10-14)$ & $170(19.54)$ & $22.70(19-25)$ \\
\hline Severe & $123(14.4)$ & $25.04(21-27)$ & 136 (15.63) & $17.33(15-19)$ & $188(21.61)$ & $29.05(26-33)$ \\
\hline Highly severe & 175 (20.11) & $32.19(\geq 28)$ & $296(34.02)$ & $24.19(\geq 20)$ & $86(9.89)$ & $38.07(\geq 34)$ \\
\hline Total & $870(100)$ & & $870(100)$ & & $870(100)$ & \\
\hline Chi-squared test & $79.586^{\star \star}$ & & $168.609^{\star \star}$ & & $108.827^{\star \star}$ & \\
\hline
\end{tabular}

headaches, high blood pressure, and skin conditions. Stress may also influence cognitive processes due to the association with elevated levels of cortisol hormone, a hormone that can influence brain functioning [28]. Therefore, high amounts of stress in medical schools predispose students for challenges and in solving interpersonal conflicts, sleeping disorders, decreased attention, reduced concentration, temptation to cheat in exams, loss of objectivity, and improper behavior like negligence [29]. Furthermore, stress in medical students can break the stability of student's health and result in illness. This can cause gastrointestinal disorders, coronary heart disease, impaired judgments, absenteeism, self-medication, and the consumption of drugs and alcohol [30]. Moreover, the relation between stressors and disease is determined by the nature, number, and persistence of the stressors and also by the individual's biological susceptibility (i.e., genetics, constitutional factors), psychosocial resources, and learned pattern of overcoming and solving.

Table 4: The relationship between social support and depression, anxiety, and stress

\begin{tabular}{llll}
\hline Domain social support groups & Depression & Anxiety & Stress \\
\cline { 2 - 4 } & Mean \pm SE & & \\
\hline Low support (0-9) & $25.95 \pm 0.94 \mathrm{a}$ & $17.16 \pm 0.86 \mathrm{a}$ & $21.28 \pm 0.81 \mathrm{a}$ \\
Borderline support (10-19) & $17.76 \pm 0.42 \mathrm{~b}$ & $16.01 \pm 0.04 \mathrm{ab}$ & $20.22 \pm 0.41 \mathrm{a}$ \\
High support (20-27) & $11.84 \pm 0.16 \mathrm{c}$ & $14.76 \pm 0.60 \mathrm{~b}$ & $19.29 \pm 0.60 \mathrm{a}$ \\
LSD & $1.858^{\star *}$ & $1.789^{*}$ & $1.855 \mathrm{NS}$ \\
$\mathrm{P}$ value & 0.0001 & 0.0501 & 0.150 \\
\hline The different letters in the same column mean that data differed significantly. ${ }^{*}(\mathrm{p} \leq 0.05),{ }^{* *}(\mathrm{p} \leq 0.01)$. \\
NS: Non-significant.
\end{tabular}

Social support has a positive role on mental health behaviors and quality of life of medical students by helping individuals feel appreciated and connected with social networks and by giving love and care to the students or by making them feel important [31]. This feeling of being socially supported can prevent and lower mental health challenges especially depression, our study revealed that the association of social support, from the family and friends, with depression was statistically significant (Tables 4 and 5). These data agreed with those reported by a study conducted in China investigated how social support is associated with levels of depression among Chinese adolescents [31].

Table 5: Correlation between social support with depression, anxiety, or stress domain

\begin{tabular}{lll}
\hline Domain & Correlation coefficient-r with social support & $p$-value \\
\hline Depression & -0.43 & $0.0001^{\text {** }}$ \\
Anxiety & -0.06 & $0.070 \mathrm{NS}$ \\
Stress & -0.05 & $0.122 \mathrm{NS}$ \\
\hline${ }^{*}$ Highly significant $(p \leq 0.01)$. NS: Non-significant. &
\end{tabular}

Moreover, a study conducted in Korea suggested that low level of social support increases the risk of depression by more than 10 times.
Furthermore, there have been an increasing number of studies that assessed depression among medical students and they revealed that depressive symptoms among medical students are higher than in the general population and students' age-matched peers [32], [33], [34], [35], [36], [37].

Nonetheless, statistical analysis highlighted a significant negative correlation between social support and anxiety as high social support would decrease psychological problems especially anxiety [38]. Thus the existence of good social support can reduce the extent to which situations are perceived as a threat to wellbeing. Social support was found to be one of the protective factors for students that could reduce the amount of anxiety and other psychological problems. Studies in China [39] and Canada [40] reported negative correlation between these two variables. Another study from New York [41] indicated that social supports from family and friends influence students' wellbeing such that these supports were found to positively affect students' academic life. However, studies in Romania [42] and Malaysia [43] revealed a negative correlation. Therefore, the findings of the present study provide evidence for the relationship between social support and anxiety as a psychological problem among students.

In this study, we also aimed to examine the impact of social support on mental health symptomatology through psychological stress. Our results showed that the social support impact on psychological stress was not significant. In contrast, significant result with negative correlation that social support can serve to buffer the impact of which was confirmed by earlier studies [44], [45]. The contrast reported in the current study might be because current was exclusively among medical students.

Those college students who become aware of tests/exams as a burden may additionally experience disturbing conditions in contrast to others who consider examinations useful and may help in their learning [46]. In addition, previous research had reported that academics/exams are common sources of stress amongst medical students [47], [48], [49]. Therefore, it may be necessary to revisit the evaluation/examination system to make it less disturbing for students.

Another important source of stress is that related to psychosocial factors. The latter may be due to time constraints for self, family, friends, and enjoyment due to the stressful medical curriculum [47], [49]. Another purpose could be inadequate recreational facilities 
provided by the university as reported by students. The students, who were stressed, mentioned that psychosocial and academic-related stressor groups had occurred more frequently [46], [47], [48], [49], [50], [51], [52], [53], [54], [55].

The amount and severity of stress experienced by medical students may vary according to the medical school environment and the students themselves such as student academic workload, pressure on academic institutions and staff, and expansion of student numbers. Leaving one's family and making a new start elsewhere also contributes to stress. As many students place great value on social and familial support, a change in environment can disrupt this support and it may take some time to find adequate substitutes [47], [49], [56], [57], [58].

\section{Limitations}

This study was carried out on the website so the participants might not reflect an accurate representation of the medical schools in Iraq and it was only filled by those who are interested in mental health and psychology. In addition, gender representation was compromised as there were $69.43 \%$ and $30.57 \%$ female and male participants, respectively.

On the other hand, although the sample size was relatively adequate for the study, a larger sample size gives an accurate perception and better understanding of the correlation between the different variables used in this study. Furthermore, random sampling technique would also give more concise representation of gender, age, and year of the study.

\section{Conclusion}

There is a high prevalence of depression, anxiety, and stress among medical students in Iraq which has impact on their daily life behaviors. Social support plays a positive role in relieving symptoms of depression and anxiety, yet it does not have such impact on stress because medical systems and curriculum represent the major stressor. Moreover, there is a need for serious interventions by the stakeholders to manage and alleviate the stress experienced by medical students in Iraq.

\section{Recommendations}

Further studies with a larger sample size are required as well as comparing the academic level of students who get adequate social support, from family and close friends, with those who do not get such support. Furthermore, the establishment of a students' support system in each medical school to help those who got stressed.

\section{References}

1. Emmons H. The Chemistry of Joy: A Three-Step Program for Overcoming Depression Through Western Science and Eastern Wisdom. New York: Simon and Schuster; 2006.

2. Gordon J. Unstuck: Your Guide to the Seven-Stage Journey Out of Depression. New York: Penguin Press; 2008.

3. Berkman LF, Glass T, Brissette I, Seeman TE. From social integration to health: Durkheim in the new millennium. Soc Sci Med. 2000;51(6):843-57. https://doi.org/10.1016/ s0277-9536(00)00065-4

PMid:10972429

4. House JS, Landis KR, Umberson D. Social relationships and health. Science. 1988;241(4865):540-5. https://doi.org/10.1126/ science. 3399889

PMid:3399889

5. Bruce ML. Psychosocial risk factors for depressive disorders in late life. Biol Psychiatry. 2002;52(3):175-84. https://doi. org/10.1016/s0006-3223(02)01410-5

PMid:12182924

6. Cohen S, Wills TA. Stress, social support, and the buffering hypothesis. Psychol Bull. 1985;98(2):310

PMid:3901065

7. European Union Public Health Information System, Dalgard OS Social Support: Occurrence; 2009. Available from: http://euphix. org. [Last accessed on 2021 Sep 20].

8. Dalgard OS, Bjørk S, Tambs K. Social support, negative life events and mental health. Br J Psychiatry. 1995;166(1):29-34. https://doi.org/10.1192/bjp.166.1.29

PMid:7894872

9. Dalgard OS. A randomized controlled trial of a psychoeducationa group program forunipolar depression in adults in Norway (NCT00319540). Clin Pract Epidemol Ment Health. 2006;2:15. https://doi.org/10.1186/1745-0179-2-15 PMid:16805912

10. Kawachi I, Berkman LF. Social ties and mental health. J Urban Health. 2001;78:458-67. https://doi.org/10.1093/jurban/78.3.458 PMid:11564849

11. Connor KM, Davidson JR. Development of a new resilience scale: The connor-davidson resilience scale (CD-RISC). Depress Anxiety. 2003;18(2):76-82. https://doi.org/10.1002/ da. 10113

PMid:12964174

12. Haddadi $P$, Besharat MA. Resilience, vulnerability and mental health. Proc Soc Behav Sci. 2010;5:639-42. https://doi. org/10.1016/j.sbspro.2010.07.157

13. Doku VC, Wusu-Takyi A, Awakame J. Implementing the mental health act in Ghana: Any challenges ahead? Ghana Med J. 2012;46(4):241-50. PMid:23661843

14. Rosenberg M. Conceiving the Self. New York: Basic Books; 1979.

15. Rosenberg M, Schooler C, Schoenbach C, Rosenberg F. Global 
self-esteem and specific self-esteem: Different concepts, different outcomes. Am Soc Rev. 1995;60:141-56.

16. Baumeister RF, Campbell JD, Krueger JI, Vohs KD. Does high self-esteem cause better performance, interpersonal success, happiness, or healthier lifestyles? Psychol Sci Public Interest. 2003;4:1-44

17. Koster A, Bosma H, Kempen GI, Penninx BW, Beekman AT, Deeg DJ, et al. Socioeconomic differences in incident depression in older adults: The role of psychosocial factors, physical health status, and behavioral factors. J Psychosom Res. 2006;61(5):619-27. https://doi.org/10.1016/j. jpsychores.2006.05.009

PMid:17084139

18. Sarason IG, Levine HM, Basham RB, Sarason BR. Assessing social support: The social support questionnaire. J Pers Soc Psychol. 1983;44:127-39.

19. SAS. Statistical Analysis System, User's Guide. Statistical. Version 9. $1^{\text {st }}$ ed. Cary NC, USA: SAS Institue Inc; 2012.

20. Rasheed AG, Hussein AG. Depression, anxiety, and stress among medical students of College of Medicine, Hawler Medical University, Erbil, Iraq. Zanco J Med Sci. 2019;23(2):143-52. https://doi.org/10.15218/zjms.2019.019

21. Kanter JW, Busch AM, Weeks CE, Landes SJ. The nature of clinical depression: Symptoms, syndromes, and behavior analysis. Assoc Behav Anal Int. 2008;31(1):1-21. https://doi. org/10.1007/BF03392158

PMid:22478499

22. Hershner SD, Chervin RD. Causes and consequences of sleepiness among college students. Nat Sci Sleep. 2014;6:7384. https://doi.org/10.2147/NSS.S62907 PMid:25018659

23. Centers for Disease Control and Prevention. Anxiety and Depression in Children. Atlanta, Georgia: Centers for Disease Control and Prevention; 2020. Available from: https://www.cdc. gov/childrensmentalhealth/depression.html. [Last accessed on 2021 Sep 27].

24. Abdulghani HM. Stress and depression among medical students: A cross-sectional study at a College in Saudi Arabia. Pak J Med Sci Q. 2008;24(1):12-7.

25. Koochaki GM, Charkazi A, Hasanzadeh A, Saedani M, Qorbani M, Marjani A. Prevalence of stress among Iranian medical students: A questionnaire survey. East Mediterr Health J. 2011;17(7):593-8.

PMid:21972483

26. Firth J. Levels and sources of stress in medical students. $\mathrm{Br}$ Med J. 1986;292(6529):1177-80. https://doi.org/10.1136/ bmj.292.6529.1177 PMid:3085772

27. American Psychological Association. How Does Stress Influence Behavior. Washington, DC: American Psychological Association; 2015. Available from: https://www.apa.org/pubs/ highlights/peeps/issue-40. [Last accessed on 2021 Sep 30].

28. Ironson G, Siegel SD. Stress and health: Psychological, behavioral, and biological determinants. Annu Rev Clin Psychol. 2005;1:607-28. https://doi.org/10.1146/annurev. clinpsy.1.102803.144141 PMid:17716101

29. Khan R, Lin JS, Mata DA. Addressing depression and suicide among physician trainees. JAMA Psychiatry. 2015;72(8):848. https://doi.org/10.1001\%2Fjamapsychiatry.2015.0643 PMid:26107537

30. O'RourkeM,HammondS. The medical studentstress profile:Atool forstressauditinmedicaltraining. MedEduc.2010;27(44):1027-37. https://doi.org/10.1111/j.1365-2923.2010.03734.x

PMid:20880372
31. Chang cw, Yuan R, Chen JK. Social support and depression among Chinese adolescents: The mediating roles of selfesteem and self-efficacy. Child Youth Serv Rev. 2018;88:1-3. https://doi.org/10.1016/j.childyouth.2018.03.001

32. Dyrbye LN, Thomas MR, Shanafelt TD. Systematic review of depression, anxiety, and other indicators of psychological distress among U.S. and Canadian medical students. Acad Med. 2006;81:354-73.

33. Toews JA, Lockyer JM, Dobson DJ, Brownell AK. Stress among residents, medical students, and graduate science (MSc/PhD) students. Acad Med. 1993;68(Suppl 10):S46-8. https://doi. org/10.1097/00001888-199310000-00042

PMid:8216630

34. Dahlin M, Joneborg N, Runeson B. Stress and depression among medical students: A cross-sectional study. Med Educ. 2005;39(6):594-604. https://doi. org/10.1111/j.1365-2929.2005.02176.x PMid: 15910436

35. Givens JL, Tjia J. Depressed medical students' use of mental health services and barriers to use. Acad Med. 2002;77(9):91821. https://doi.org/10.1097/00001888-200209000-00024 PMid:12228091

36. Yusoff MS, Abdul Rahim AF, Yaacob MJ. Prevalence and sources of stress among Universiti Sains Malaysia medical students. Malays J Med Sci. 2010;17(1):30-7.

PMid:22135523

37. Clark DC, Zeldow PB. Vicissitudes of depressed mood during four years of medical school. JAMA. 1988;260(17):2521-8. PMid:3172426

38. Lakey B, Cohen S. Social support theory and measurement. In: Cohen S, Underwood LG, Gottlieb BH, editors. Social Support Measurement and Interventions: A Guide for Health and Social Scientists. New York: University Press; 2000.

39. Tao S, Dong Q, Pratt MW, Hunsberger B, Pancer SM. Social support: Relations to coping and adjustment during the transition to university in the Peoples Republic of China. J Adolesc Res. 2000;5(1):123-44.

40. Nahid OW, Sarkis E. Types of social support: Relation to stress and academic achievement among prospective teachers. Can J Behav Sci. 1994;26(1):1-10. https://doi. org/10.1037/0008-400X.26.1.1

41. Silbereisen RK, Todt E. The broader context of social influence in adolescence. In: Silbereisen RK, Todt E, editors. Adolescence in Context: The Interplay of Family, School, Peers, and Work in Adjustment. New York: Springer-Verlag Inc.; 1994.

42. Dughi ST, Demeter E, Vancu GS. Perceived social support and anxiety: A correlational analysis. Arad, Romania: Aurel Vlaicu University of Arad, Faculty of Educational Sciences, Psychology and Social Sciences; 2020.

43. Yasin MA, Yasin SM, Dzulkifli MA. The relationship between social support and psychological problems among students. Int J Bus Soc Sci. 2010;1:111-6.

44. Crockett LJ, Iturbide MI, Stone RA, McGinley M, Raffaelli M, Carlo G. Acculturative stress, social support, and coping: Relations to psychological adjustment among Mexican American college students. Cult Divers Ethnic Minority Psychol. 2007;13(4):347-55. https://doi.org/10.1037/1099-9809.13.4.347 PMid: 17967103

45. Mallinckrodt B, Leong FT. International graduate students, stress, and social support. J Coll Stud Dev. 1992;33(1):71-8.

46. Stewart SM, Lam TH, Betson CL, Wong CM, Wong AM. A prospective analysis of stress and academic performance in the first 2 years of medical school. Med Educ. 1999;33(4):243-50. https://doi.org/10.1046/j.1365-2923.1999.00294.x

PMid: 10336754 
47. Al-Zobaidy MA, Chandratilake M. Validity and Utility of Dundee Ready Educational Environment Measure in the context of Iraqi Medical Education. MSc Thesis, Faculty of Medicine, Dentistry and Nursing, University of Dundee; 2017.

48. Al-Zobaidy MA, Mostafa A, Hussien Z, Redah MH, Adnan T, Mohammed $\mathrm{H}$. Prevalence of stress and coping behaviors among medical students at University of AL-Qadisiyah. Medico Legal Update. 2020;20(1):535. https://doi.org/10.37506/mlu. v20i1.535

49. Al-Zobaidy MA. Utility of dundee ready educational environment measure for evaluation of nursing educational environment in Iraq. Indian J Public Health Res Dev. 2018;9(7):165-7.

50. Shaikh BT, Kahloon A, Kazmi M, Khalid H, Nawaz K, Khan N, et al. Students, stress and coping strategies: A case of Pakistani medical school. Educ Health (Abingdon). 2004;17:346-53. https://doi.org/10.1080/13576280400002585

PMid:15848822

51. Cohen S, Kamarck T, Mermelstein R. A global measure of perceived stress. J Health Soc Behav. 1983;24(4):385-96. PMid:6668417

52. Guthrie EA, BlackD, Shaw CM, Hamilton J, Creed FH, Tomenson B. Embarking upon a medical career: Psychological morbidity in first year medical students. Med Educ. 1995;29(5):337-41. https://doi.org/10.1111/j.1365-2923.1995.tb00022.x

\section{PMid:8699970}

53. Stewart SM, Betson C, Marshall I, Wong CM, Lee PW, Lam $\mathrm{TH}$. Stress and vulnerability in medical students. Med Educ. 1995;29(2):119-27. https://doi.org/10.1111/j.1365-2923.1995. tb02814.x

PMid:7623698

54. Ko SM, Kua EH, Fones CS. Stress and the undergraduates. Singapore Med J. 1999;40(10):627-30.

PMid:10741189

55. Coles C. Medicine and stress. Med Educ. 1994;28:3-4. https:// doi.org/10.1111/j.1365-2923.1994.tb02677.x

PMid:8208165

56. Ortmeier BG, Wolfgang AP, Martin BC. Career commitment, career plans, and perceived stress: A survey of pharmacy students. Am J Pharm Educ. 1991;55:138-42.

57. Wolfgang AP. The health professions stress inventory. Psychol Rep. 1988;62(1):220-2. https://doi.org/10.2466/pr0.1988.62.1.220 PMid:3363060

58. Wolfgang AP, Perri Wolfgang CF. Job related stress experienced by hospital pharmacists and nurses. Am J Hosp Pharm. 1988;45(6):1342-5.

PMid:3414703 